
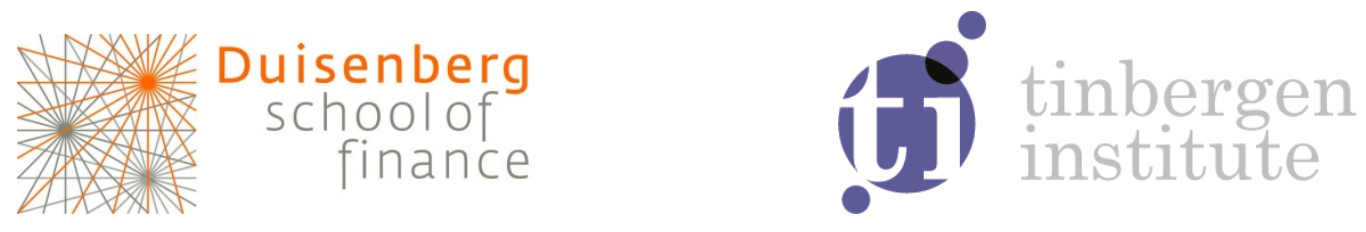

Duisenberg school of finance - Tinbergen Institute Discussion Paper

TI 12-146/DSF 49/IV

Banking Competition and Soft Budget

Constraints:

How Market Power can threaten

Discipline in Lending

Stefan Arping

Faculty of Economics and Business, University of Amsterdam, and Tinbergen Institute. 
Tinbergen Institute is the graduate school and research institute in economics of Erasmus University Rotterdam, the University of Amsterdam and VU University Amsterdam.

More TI discussion papers can be downloaded at http://www.tinbergen.nl

Tinbergen Institute has two locations:

Tinbergen Institute Amsterdam

Gustav Mahlerplein 117

1082 MS Amsterdam

The Netherlands

Tel.: +31(0)205251600

Tinbergen Institute Rotterdam

Burg. Oudlaan 50

3062 PA Rotterdam

The Netherlands

Tel.: +31(0)10 4088900

Fax: +31(0)104089031

Duisenberg school of finance is a collaboration of the Dutch financial sector and universities, with the ambition to support innovative research and offer top quality academic education in core areas of finance.

DSF research papers can be downloaded at: http://www.dsf.nl/

Duisenberg school of finance

Gustav Mahlerplein 117

1082 MS Amsterdam

The Netherlands

Tel.: +31(0)20 5258579 


\title{
Banking Competition and Soft Budget Constraints: How Market Power Can Threaten Discipline in Lending
}

\author{
Stefan Arping*
}

December 19, 2012

\begin{abstract}
In imperfectly competitive credit markets, banks can face a tradeoff between exploiting their market power and enforcing hard budget constraints. As market power rises, banks eventually find it too costly to discipline underperforming borrowers by stopping their projects. Lending relationships become "too cozy", interest rates rise, and loan performance deteriorates.
\end{abstract}

Keywords: Banking Competition, Soft Budget Constraint Problem, Moral Hazard JEL Classification: G2, G3

*University of Amsterdam, Faculty of Economics and Business, Finance Group, Roetersstraat 11, 1018 WB Amsterdam, The Netherlands, e-mail: s.r.arping@uva.nl, and Tinbergen Institute 


\section{Introduction}

A central issue in finance pertains to the efficient industrial organization of banking. As in other industries, market power in the banking sector can give rise to price distortions and as such impair allocative efficiency. High loan rates can depress real investment, ${ }^{1}$ stifle the incentives of borrowers to add value to their projects, and induce them to engage in reckless risk-taking (e.g., Boyd and De Nicolo 2005). Furthermore, market power can impair Xefficiency, albeit not necessarily so (e.g., Schmidt 1997). Lastly, there is a large literature arguing that the degree of banking competition matters for financial stability. ${ }^{2}$

Our aim in this article is to examine an issue that has been largely overlooked by the literature: the impact of market power on banks' commitment to maintain discipline in corporate lending. We argue that loan market power, to the extent that it is exploited, can give rise to a "soft budget constraint" problem: as banks hold larger stakes in borrowers' projects, they become less committed to penalize underperforming borrowers by exercising foreclosure threats and stopping their projects. This can have negative implications for borrower incentives ex ante. Thus, when operating in imperfectly competitive loan markets, banks can face a tradeoff between exploiting their market power and enforcing hard budget constraints. We develop a simple model to analyze this tradeoff.

The key finding is that small changes in loan market power, while having little effect on a lender's profit, can have a dramatic impact upon loan rates, loan performance, and economic efficiency. Specifically, we show that, to the extent that foreclosure threats are credible in perfectly competitive loan markets, there is a critical level of loan market power such that lenders enforce hard budgets constraints if and only if loan market power is below this threshold. As loan market power rises above the threshold, it becomes too costly for

\footnotetext{
${ }^{1}$ However, it also has been argued that market power can improve credit availability by enhancing banks' incentive to invest in relationship building (cf., Petersen and Rajan 1995).

${ }^{2}$ For recent contributions to the theory literature, see, among others, Boyd and De Nicolo (2005), Martinez-Miera and Repullo (2010), Wagner (2010), and Hakenes and Schnabel (2011). On the empirical front, see, e.g., Berger et al. (2009), Schaeck et al. (2009), and Beck et al. (2012).
} 
lenders to stay committed to stop underperforming borrowers' projects. Lending relationships become overly cozy, interest rates rise sharply, and loan performance deteriorates.

The thrust of the soft budget constraint problem has to do with the adverse effect of the ex post continuation of underperforming projects on incentives ex ante. It has been analyzed by, among others, Dewatripont and Maskin (1995), and it is central to a large corporate finance literature on intervention threats and multiple lenders (see, among others, Berglöf and von Thadden 1994, Dewatripont and Tirole 1994, Bolton and Scharfstein 1996, and, closest related to our setting, Repullo and Suarez 1998). ${ }^{3}$ The tradeoff between rent extraction and discipline in lending (hard budget constraints) proposed in our paper is novel to this literature. This article also relates to recent work by Loranth and Morrison (2012) who examine tying of lending to investment banking by universal banks. In their model, tying may alleviate credit constraints by assuring the lender of a larger share of the surplus, but it may also create a soft budget constraint problem in that it undermines the lender's commitment to stop poorly performing projects. Interestingly, they show that when investment banking is uncompetitive, the former effect dominates and there is too little tying, whereas when investment banking is competitive, there is too much tying.

The remainder of this article is organized as follows. The next section presents the model. Sections 3 and 4 analyze the model and derive the loan market equilibrium. Section 5 concludes and provides a brief discussion of the model's empirical implications.

\section{Model}

There is universal risk-neutrality and no discounting. We consider an entrepreneur who is endowed with a project. At date 0 , the project requires a start-up investment of $\$ 1$. If continued until maturity (date 2), the project will either succeed and generate a return $\Pi>0$, or it will fail and yield a return of zero. Conversely, if the project is not continued

\footnotetext{
${ }^{3}$ The soft budget constraint problem and it variants are also at the heart of recent debates concerning the moral hazard implications of bank or country bailouts.
} 
until maturity, then it is terminated at date 1 for liquidation value $L<1{ }^{4}$ The probability of project success at maturity depends upon the entrepreneur's non-contractible effort, which is to be exerted right after the project is undertaken: if the entrepreneur exerts effort $e \in[0,1]$ then the probability of success is equal to $e .^{5}$ The entrepreneur incurs a private effort cost $\psi(e)$, which is increasing and strictly convex, and satisfies the following standard regularity conditions: $\psi(0)=\psi^{\prime}(0)=0, \psi^{\prime}(1) \leq \Pi$, and $\psi^{\prime \prime \prime}(e) \geq 0$. We assume that, conditional on the entrepreneur exerting efficient effort and the project being continued until maturity, project NPV is positive:

$$
\max _{e}\{e \Pi-\psi(e)\}>1
$$

For later reference, let $e^{F B}$ denote the efficient effort level.

The entrepreneur has personal funds $w<1$ (e.g., from family sources); she thus needs to borrow 1-w. There are two types of lenders in our setting: an "incumbent" lender and many "non-incumbent" lenders. The entrepreneur has an intrinsic preference to undertake her project with the incumbent lender. This could stem from, e.g., prior business relationships, spatial product differentiation, or geographical proximity. Formally, we assume that if the entrepreneur borrows funds from a lender other than the incumbent she incurs a private transaction (or "switching") cost $s>0$. No such cost is incurred if she undertakes her project with the incumbent lender. Non-incumbent lenders compete à la Bertrand and are willing to provide funds as long as they can expect to break even.

The initial loan contracting stage is as follows. The incumbent lender first makes a loan contract offer to the entrepreneur, which the entrepreneur accepts or rejects. If the entrepreneur rejects she seeks funding from a non-incumbent lender. As non-incumbent lenders compete à la Bertrand, they quote competitive loan rates. The downside of securing

\footnotetext{
${ }^{4}$ The date 2 liquidation value is normalized to zero.

${ }^{5}$ An alternative setup, which would be closer in spirit to the soft budget constraint literature (e.g., Dewatripont and Maskin 1995), is as follows: just before date 2 the project requires a continuation investment $K \approx \Pi$ with probability $1-e$ and zero with probability $e$. If continued until date 2 and not liquidated at date 1 for value $L$ the project yields a cash flow $\Pi$. This setup is equivalent to the model considered here.
} 
funding elsewhere is that the entrepreneur incurs the transaction cost $s$. Thus, the higher is $s$, the stronger is the incumbent lender's loan pricing power.

While effort is non-contractible, it is assumed to be privately observable to the entrepreneur's lender (e.g., because of routine due diligence). Non-contractibility of effort gives rise a standard moral hazard problem (as is standard, the entrepreneur is protected by limited liability). Observability of effort has the advantage that the lender can potentially improve the entrepreneur's incentive to exert effort by threatening to terminate the project at the interim stage should she underprovide effort. To allow for this possibility, we consider financial contracts under which the lender is given the right to terminate the project at date 1 (it will become clear below that doing so is always optimal in our setting). One can think of this as the loan contract containing a loosely defined material adverse change clause that gives the lender discretion to force default and liquidation at date 1. A financial contract then specifies a repayment $R \leq \Pi$ due at date 2 and the lender's share $R_{0} \leq L$ of the liquidation proceeds in the event of project termination at date 1.

For the sake of simplicity, we do not allow for contract renegotiation, but we do discuss below that our results are robust to the possibility of renegotiation.

\section{The entrepreneur's outside option}

We start with deriving the equilibrium under the entrepreneur's outside option. Suppose the entrepreneur rejects the incumbent lender's loan contract offer and seeks funding from a non-incumbent. As non-incumbent lenders compete à la Bertrand, the optimal loan contract with a non-incumbent lender maximizes the entrepreneur's payoff

$$
\begin{aligned}
\max _{\left(e^{*}, R, R_{0} \leq L\right)} & U\left(e^{*}\right)=e^{*}(\Pi-R)-\psi\left(e^{*}\right) \\
\text { s.t. } & \\
& e^{*} R=1-w \\
& e^{*} R \geq R_{0}
\end{aligned}
$$




$$
e^{*}=\arg \max _{e} U(e)
$$

where $e^{*}$ denotes the (candidate) equilibrium effort level, (IR) is the lender's binding break even constraint, $(\mathrm{CO})$ ensures that in equilibrium the lender has to incentive to terminate the project (which cannot be an equilibrium outcome, since $L<1$ ), and (IC) is the entrepreneur's incentive constraint. To derive the entrepreneur's payoff $U(e)$ from exerting effort $e$, notice that the lender will continue the project if and only if $e R \geq R_{0}$. Thus,

$$
U(e)= \begin{cases}e(\Pi-R)-\psi(e) & \text { for } e \geq R_{0} / R \\ L-R_{0}-\psi(e) & \text { for } e<R_{0} / R\end{cases}
$$

Notice that the entrepreneur's payoff function entails a discontinuity at the critical effort level where the lender is just indifferent between project termination and continuation. We have the following result:

Lemma 1 Suppose the entrepreneur rejects the incumbent lender's loan contract offer and seeks funding from a non-incumbent (at private cost s). Then:

(i) For $L \geq 1-w$, the first best can be achieved. An optimal contract is $R_{0}=1-w$ and $R=(1-w) / e^{F B}$. In equilibrium, the entrepreneur exerts efficient effort $e^{F B}$ and the project is continued.

(ii) For $L<1-w$, the first best cannot be achieved. If investment is feasible and optimal, equilibrium effort $e^{\text {out }}$ is given by the largest solution of

$$
\Pi-\frac{1-w}{e^{*}}=\psi^{\prime}\left(e^{*}\right)
$$

and is strictly inferior to $e^{F B}$. An optimal contract is $R=(1-w) / e^{\text {out }}$ and $R_{0}=L$.

Proof. See Appendix.

The first part of the lemma shows how the threat of termination, if credible, resolves the entrepreneur's moral hazard problem. To see the mechanism, notice that under the optimal contract the lender is just indifferent between project continuation and termination if and 
only if the entrepreneur exerts efficient effort. For $e<e^{F B}$, the lender would exercise the foreclosure threat and terminate the project. Faced with this treat, the entrepreneur has no incentive to underperform. ${ }^{6}$ The second part of the lemma shows what can be implemented when the asset liquidation value is such that the lender cannot recoup his investment outlay by terminating the project and foreclosing assets. In this case, the lender necessarily strictly prefers to continue the project in equilibrium, i.e., (CO) holds with strict inequality. As the lender strictly prefers to continue the project in equilibrium, there is a constant $\epsilon>0$ such that the project will be continued for any $e \geq e^{*}-\epsilon$. In other words, some outof-equilibrium deviations from equilibrium effort would not be penalized: the threat of termination lacks credibility. Thus, the entrepreneur's payoff from exerting effort $e \geq e^{*}-\epsilon$ is $U(e)=e(\Pi-R)-\psi(e)$, and hence incentive-compatibility requires

$$
U^{\prime}\left(e^{*}\right)=\Pi-R-\psi^{\prime}\left(e^{*}\right)=0
$$

This is merely the incentive constraint in the absence of termination threats, which shows that the threat of termination is no longer relevant for incentives.

Our aim below is to show that loan market power may impair the incumbent lender's commitment to discipline shirking. Thus, to make the analysis interesting, we assume in what follows that in perfectly competitive financial markets foreclosure threats are credible. Specifically, we assume $L>1-w$. Thus, under her outside option the entrepreneur will exert efficient effort $e^{F B}$ and, by (1), derive a payoff of

$$
V=e^{F B} \Pi-(1-w)-\psi\left(e^{F B}\right)>w
$$

\footnotetext{
${ }^{6}$ This result is robust to the possibility of renegotiation. If renegotiation were feasible, the project would not be terminated for all $e<e^{F B}$. However, the entrepreneur would have to fully compensate the lender for the cost of shirking. This would ensure that the entrepreneur has no incentive to shirk.
} 


\section{Loan market equilibrium}

We now turn to the contracting problem between the entrepreneur and the incumbent lender. The incumbent lender's optimization problem is to maximize his profit

$$
\begin{aligned}
\max _{\left(e^{*}, R, R_{0} \leq L\right)} & e^{*} R-(1-w) \\
\text { s.t. } & \\
& U\left(e^{*}\right)=e^{*}(\Pi-R)-\psi\left(e^{*}\right) \geq V-s \\
& e^{*} R \geq R_{0} \\
& e^{*}=\arg \max _{e} U(e)= \begin{cases}e(\Pi-R)-\psi(e) & \text { for } e \geq R_{0} / R \\
L-R_{0}-\psi(e) & \text { for } e<R_{0} / R\end{cases}
\end{aligned}
$$

where (IR) now denotes the entrepreneur's participation constraint. Here, we assume $s \leq V-w$ so that the threat to secure funding elsewhere is credible. As above, (CO) ensures that in equilibrium the lender has no incentive to terminate the project, and (IC) is the entrepreneur's incentive constraint. In what follows, we say that the lender imposes a hard budget constraint if and only if he designs the contract such that in equilibrium he just indifferent between project continuation and termination, $e^{*} R=R_{0}$. Notice that this is a matter of choice for the incumbent lender as he could always offer the competitive loan contract. This contract would be accepted by the entrepreneur, it would induce efficient effort, and it would ensure that the incumbent lender breaks even on his investment. However, as we shall see now, the incumbent lender will do better with another contract.

Lemma 2 Suppose the incumbent lender imposes a hard budget constraint. Then the optimal contract entails

$$
R_{0}=\min [1-w+s, L] \text { and } R=R_{0} / e^{F B}
$$

In equilibrium, the entrepreneur exerts efficient effort $e^{F B}$ and the project is continued.

Proof. Suppose (CO) holds with equality, i.e., $R=R_{0} / e^{*}$, and let us assume and verify later that (IC) is slack. The incumbent lender's problem reduces to

$$
\max _{\left(e^{*}, R_{0}\right)} \quad R_{0}-(1-w)
$$


s.t.

$$
\begin{aligned}
& R_{0} \leq e^{*} \Pi-\psi\left(e^{*}\right)-\left(e^{F B} \Pi-\psi\left(e^{F B}\right)\right)+1-w+s \\
& R_{0} \leq L
\end{aligned}
$$

where (IR') is the reduced form participation constraint. This problem is obviously solved for $e^{*}=e^{F B}$ and the contract stated in the lemma. To show that (IC) is slack, notice that $U(e)$ is maximized at $e^{F B}$ since $\left.U^{\prime}\left(e^{F B}\right)\right|_{e \geq e^{F B}}<0$ and $\left.U\left(e^{F B}\right)\right|_{e \geq e^{F B}}=e^{F B} \Pi-R_{0}-\psi\left(e^{F B}\right)>$ $\max _{e} L-R_{0}-\psi(e)=L-R_{0}$ by $(1)$ and $L<1$.

Clearly, for $s \leq L-(1-w)$, the lender cannot do better with another contract: the entrepreneur's rent is fully extracted (her participation constraint holds with equality) and efficient effort is implemented; thus, the lender achieved the first best for himself. The lender's profit is $R_{0}-(1-w)=s$. However, for $s>L-(1-w)$, the lender would leave the entrepreneur a strictly positive rent if he imposed a hard budget constraint. The lender may then prefer to not impose a hard budget constraint and charge a higher interest rate.

We now investigate this tradeoff. Let $s>L-(1-w)$ and suppose the lender does not enforce a hard budget constraint, i.e., $e^{*} R>R_{0}$. Hence, incentive-compatibility requires

$$
\Pi-R=\psi^{\prime}\left(e^{*}\right)
$$

We show in the Appendix that (IC') is sufficient for incentive-compatibility. The incumbent lender's problem reduces to

$$
\begin{array}{cc}
\max _{e^{*}} & e^{*}\left(\Pi-\psi^{\prime}\left(e^{*}\right)\right)-(1-w) \\
\text { s.t. } & \\
& e^{*} \psi^{\prime}\left(e^{*}\right)-\psi\left(e^{*}\right) \geq V-s
\end{array}
$$

where we substituted for $R=\Pi-\psi^{\prime}\left(e^{*}\right)$. Let $e^{M}$ denote the solution of the unconstrained problem, i.e., the unique solution of the first order condition

$$
\Pi-\psi^{\prime}\left(e^{*}\right)-e^{*} \psi^{\prime \prime}\left(e^{*}\right)=0
$$


Let $e^{S B}(s)$ denote the unique solution of (IR"). Notice that $e^{S B}(s)$ is strictly decreasing in $s$ and that (IR") is slack if and only if $e^{S B}(s) \leq e^{M}$. Let us assume $e^{S B}(V-w)<e^{M}$ so that (IR") is slack for some $s<V-w$ (recall that $s=V-w$ is the highest level of market power). There thus is a threshold $\check{s}<V-w$ such that (IR") is slack if and only if $s \geq \check{s}$.

In summary, if the lender does not enforce a hard budget constraint his profit is

$$
e^{M}\left(\Pi-\psi^{\prime}\left(e^{M}\right)\right)-(1-w)
$$

or lower (since (IR") is binding for $s<\check{s}$ ). The lender's profit from imposing a hard budget constraint is $L-(1-w)$. Therefore, if $e^{M}\left(\Pi-\psi^{\prime}\left(e^{M}\right)\right)-(1-w) \leq L-(1-w)$ the lender will always impose a hard budget constraint, regardless of his loan pricing power. To make the analysis interesting, let us assume

$$
e^{M}\left(\Pi-\psi^{\prime}\left(e^{M}\right)\right)>L
$$

Thus, if (IR") is slack the lender does not enforce a hard budget constraint. Conversely, if (IR") is binding, the lender faces a tradeoff between discipline (hard budget constraint) and rent extraction. The following result shows how this tradeoff is resolved:

Proposition 1 Suppose (3) holds. Then there is a loan market power threshold $\hat{s}>L-$ $(1-w)$ such that

(i) For $s \leq \hat{s}$, the incumbent lender imposes a hard budget constraint and elicits efficient effort $e^{F B}$. The optimal contract entails $R=\min [L, 1-w+s] / e^{F B}$.

(ii) For $s>\hat{s}$, the incumbent lender does not impose a hard budget constraint and elicits effort $\max \left[e^{S B}(s), e^{M}\right]<e^{F B}$, where $e^{S B}(s)$ solves (IR") with equality and $e^{S B}(\hat{s})>$ $e^{M}$. The optimal contract entails $R=\Pi-\psi^{\prime}\left(\max \left[e^{S B}(s), e^{M}\right]\right)$.

Furthermore, $\lim _{s \rightarrow \hat{s}} e^{S B}(s) R=L$, i.e., the lender's profit is continuous in $s$.

Proof. See Appendix. 
Figure 1 provides an illustration. As long as the incumbent lender's loan market power is low, $s \leq \hat{s}$, he imposes a hard budget constraint and elicits efficient effort. As the lender's market power increases, it eventually becomes too costly for the lender to impose a hard budget constraint. At the critical threshold level $\hat{s}$, the lender gives up on enforcing hard budget constraints. Foreclosure threats are no longer credible. ${ }^{7}$ The loan rate jumps upwards and loan performance (effort) jumps downwards. Thus, small changes in loan market power, while having little impact on the lender's profit, can have a dramatic impact on efficiency: a small increase in loan market power from $\hat{s}-\epsilon$ to $\hat{s}+\epsilon$ results in much higher loan rates and at the same time much lower loan performance.

As loan market power increases further, the equilibrium outcome is determined by the usual tradeoff between pricing power exploitation and incentives. The entrepreneur's participation constraint is first binding, and hence the loan rate is strictly increasing and effort is strictly decreasing in $s$. At some critical level $\check{s}$, it becomes too costly for the lender to further increase the loan rate as doing so would have a too adverse impact on incentives.

Overall, we have two regimes: a hard budget constraint regime and a soft budget constraint regime. In the first regime, the lender is committed to discipline underperformance, loan performance is strong, and loan rates are low. The second regime, which prevails in relatively uncompetitive loan markets, is characterized by overly cozy lending relationships, substantially higher loan rates, poor incentives, and deteriorated loan performance.

Table 1 reports loan performance, loan rates, the incumbent lender's profit, and the entrepreneur's payoff for various levels of loan market power (let $s^{\prime}=L-(1-w)$ ). Within the hard budget constraint regime $(s \leq \hat{s})$, the loan rate is first increasing in loan market

\footnotetext{
${ }^{7}$ From the literature on multiple lenders (see the references mentioned in the Introduction), it is well known that financing a project with multiple investors and allocating liquidation control and cash flow rights to one lender can have positive implications for the credibility of foreclosure threats. This solution, however, does not work in our setting to the extent that the entrepreneur would incur the transaction cost if she secured funding not only from the incumbent lender but also elsewhere. She could then straightaway secure funding from non-incumbent lenders. More generally, dispersed debt structures and unsecured debt financing may simply be infeasible or too costly, in particular for firms that rely on bank funding.
} 


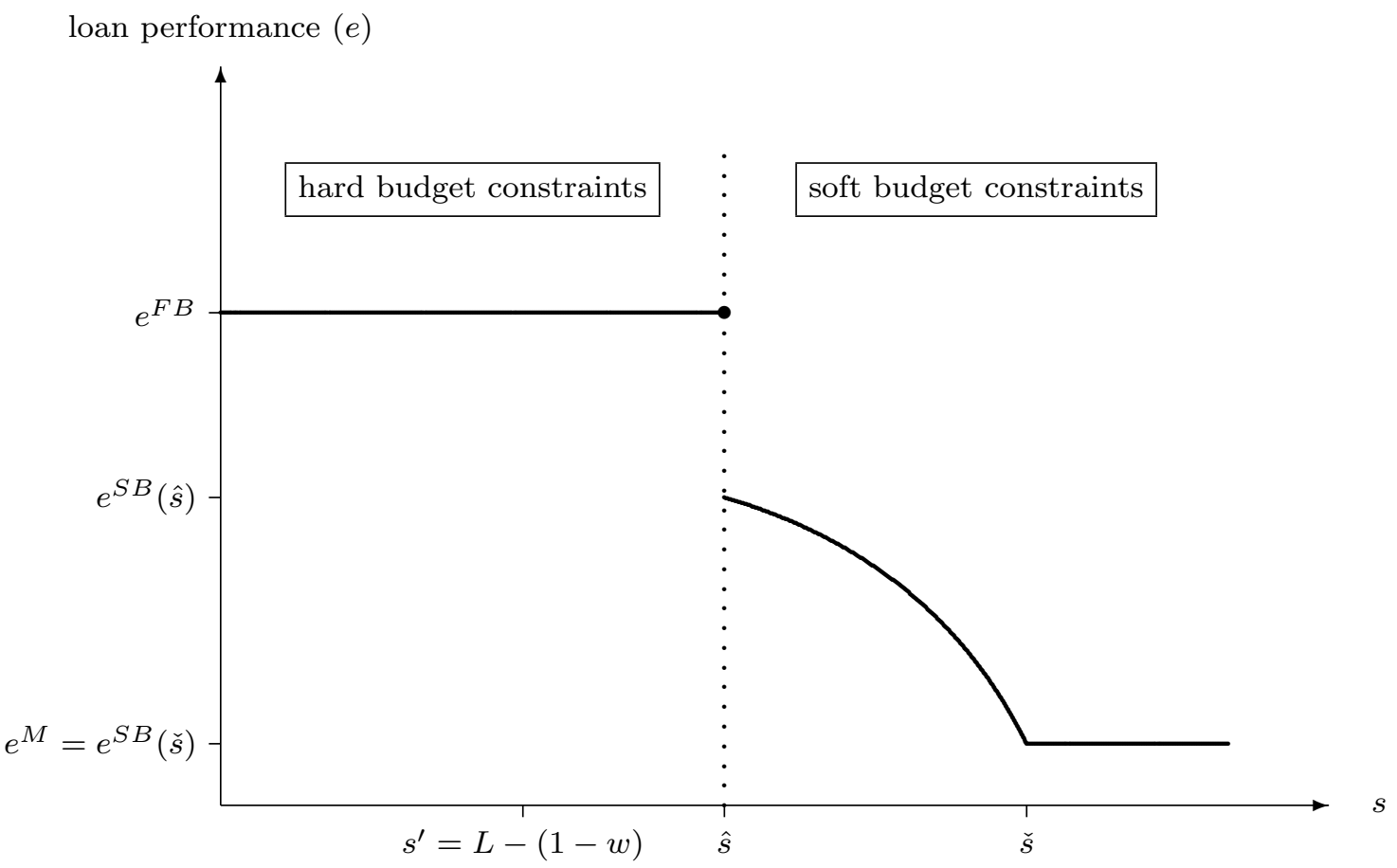

Figure 1: Loan Market Power and Loan Performance 


\begin{tabular}{l|c|c|c|c} 
Market power & Effort & $R$ & Lender's profit & Entrepreneur's payoff \\
\hline \hline$s \leq s^{\prime}$ & $e^{F B}$ & $(1-w+s) / e^{F B}$ & $s$ & $V-s$ \\
$s \in\left(s^{\prime}, \hat{s}\right]$ & $e^{F B}$ & $L / e^{F B}$ & $s^{\prime}=L-(1-w)$ & $V-s^{\prime}$ \\
$s \in(\hat{s}, \check{s}]$ & $e^{S B}(s)$ & $\Pi-\psi^{\prime}\left(e^{S B}(s)\right)$ & $e^{S B}(s) \Pi-\psi\left(e^{S B}(s)\right)-(V-s)-(1-w)$ & $V-s$ \\
$s>\check{s}$ & $e^{S B}(\check{s})$ & $\Pi-\psi^{\prime}\left(e^{S B}(\check{s})\right)$ & $e^{S B}(\check{s}) \Pi-\psi\left(e^{S B}(\check{s})\right)-(V-\check{s})-(1-w)$ & $V-\check{s}$
\end{tabular}

Table 1: Equilibrium outcomes

power and then flat. Notice that the increase in the loan rate does not have an adverse impact upon incentives. This is because the credible threat of foreclosure ensures that the entrepreneur's incentive to exert effort is aligned with the lender's interests. For $s>\hat{s}$, foreclosures threats are no longer credible. The loan rate is again first increasing in loan market power and then flat. Thus, as market power increases from zero, the entrepreneur's participation constraint is first binding, then slack, then binding, and finally again slack.

\section{Conclusion}

We have presented a simple model to illustrate how market power in banking can threaten discipline in lending. The key insight is that a small increase in loan market power, while having little effect on a lender's profit, can have a deleterious impact upon incentives, delinquency rates, and economic welfare.

The analysis yields a testable empirical implication: measures aimed at enhancing bank competition (such as removing barriers to entry) are most likely to yield large efficiency gains when the degree of loan market competition is at intermediate levels. Taken at face value, the model predicts that if loan market competition is already intense, a further increase in competition should have no real effects. ${ }^{8}$ Likewise, if the intensity of competition is very low the benefits of competition-enhancing measures may be relatively small. Conversely, if the degree of competition is at intermediate levels, then there is the potential that

\footnotetext{
${ }^{8}$ However, while an increase in the loan rate has no effect on effort in the hard budget constraint regime, it could have an adverse effect on ex ante incentives to innovate and discover positive NPV projects.
} 
competition-enhancing regulatory reforms move the equilibrium from the soft budget constraint regime to the hard budget constraint regime. The corresponding real efficiency gains would be substantial. Thus, in a cross-country empirical setting where measures of corporate performance gains (such as changes in return on assets, as in, e.g., Bertrand, Schoar, and Thesmar 2007) following competition-enhancing regulatory reforms are regressed on measures of banking competition prior to the reforms, the model would predict an inversely U-shaped relationship between the two measures.

\section{References}

Beck, T., De Jonghe, O., and G. Schepens, 2012, Bank competition and stability: Cross-country heterogeneity, Journal of Financial Intermediation, forthcoming.

Berger, A., Klapper, L., and R. Turk-Ariss, 2009, Bank competition and financial stability, Journal of Financial Services Research 35, 99-118.

Berglöf, E., and E. von Thadden, 1994, Short-term versus long-term interests: Capital structure with multiple investors, Quarterly Journal of Economics 109, 1055-1084.

Bertrand, M., Schoar, A., and D. Thesmar, 2007, Banking deregulation and industry structure: Evidence from the French banking reforms of 1985, Journal of Finance 62, 597-628.

Bolton, P., and D. Scharfstein, 1996, Optimal debt structure and the number of creditors, Journal of Political Economy 104, 1-25.

Boyd, J., and G. De Nicolo, 2005, The theory of bank risk taking and competition revisited, Journal of Finance 60, 1329-1343.

Dewatripont, M., and E. Maskin, 1995, Credit and efficiency in centralized and decentralized 
economies, Review of Economic Studies 62, 541-555.

Dewatripont, M., and J. Tirole, 1994, A theory of debt and equity: Diversity of securities and manager-shareholder congruence, Quarterly Journal of Economics 109, 1027-1054.

Hakenes, H., and I. Schnabel, 2011, Capital regulation, bank competition, and financial stability, Economics Letters 113, 256-258.

Loranth, G., and A. Morrison, 2012, Tying in universal banks, Review of Finance 16, 481-516.

Martinez-Miera, D., and R. Repullo, 2010, Does competition reduce the risk of bank failure?, Review of Financial Studies 23, 3638-3664.

Petersen, M., and R. Rajan, 1995, The effect of credit market competition on lending relationships, Quarterly Journal of Economics 110, 407-443.

Repullo, R., and J. Suarez, 1998, Monitoring, liquidation, and security design, Review of Financial Studies 11, 163-187.

Schaeck, K., Cihak, M., and S. Wolfe, 2009, Are competitive banking systems more stable?, Journal of Money, Credit, and Banking 41, 711-734.

Schmidt, K., 1997, Managerial incentives and product market competition, Review of Economic Studies 64, 191-213.

Wagner, W., 2010, Loan market competition and bank risk-taking, Journal of Financial Services Research 37, 71-81. 


\section{Appendix}

\section{Proof of Lemma 1}

To complete the proof of part (i) of the lemma it suffices to show that $e^{F B}$ is incentive compatible. Given the contract stated in the lemma, the entrepreneur's payoff function is

$$
U(e)= \begin{cases}e\left(\Pi-(1-w) / e^{F B}\right)-\psi(e) & \text { for } e \geq e^{F B} \\ L-(1-w)-\psi(e) & \text { for } e<e^{F B}\end{cases}
$$

This is maximized at $e^{F B}$ since $\left.U^{\prime}\left(e^{F B}\right)\right|_{e \geq e^{F B}}<0$ and $\left.U\left(e^{F B}\right)\right|_{e \geq e^{F B}}=e^{F B} \Pi-(1-w)-\psi\left(e^{F B}\right)>$ $\max _{e} L-(1-w)-\psi(e)=L-(1-w)$ by $(1)$ and $L<1$.

To prove part (ii) of the lemma, notice that if $L<1-w$ we must have $e^{*} R>L$; otherwise, the lender could not possibly break even. Let then $R_{0}=L$. The entrepreneur's payoff function is

$$
U(e)= \begin{cases}e\left(\Pi-(1-w) / e^{*}\right)-\psi(e) & \text { for } e \geq e^{\prime}=e^{*} L /(1-w)>e^{*} \\ -\psi(e) & \text { for } e<e^{\prime}\end{cases}
$$

where $R=(1-w) / e^{*}$ is the lender's claim. Thus, $e^{*}$ is incentive compatible if and only if

$$
\varphi\left(e^{*}\right)=\Pi-(1-w) / e^{*}-\psi^{\prime}\left(e^{*}\right)=0
$$

and $U\left(e^{*}\right)=e^{*} \Pi-(1-w)-\psi\left(e^{*}\right)>0$. Yet, $e^{*} \Pi-(1-w)-\psi\left(e^{*}\right) \geq w>0$; otherwise, the project would not have been undertaken in the first place. Thus, (4) is necessary and sufficient for incentive-compatibility. Notice that $\varphi(0)<0, \varphi(1)<0$, and that $\varphi\left(e^{*}\right)$ is strictly concave. Thus, (4) has at most two solutions. Since any such solution is inferior to the unconstrained optimum $e^{F B}$, the optimum is given by the largest solution. Investment is feasible and optimal if and only if (4) has a solution and project NPV is non-negative at the largest solution of (4). Both conditions will be satisfied for $\Pi$ sufficiently large.

\section{Proof of Proposition 1}

We know from the text that for $s \leq L-(1-w)$ the lender will impose a hard budget constraint. Thus, let $s>L-(1-w) \equiv s^{\prime}$ and, w.l.o.g., $R_{0}=L$, and suppose the lender does not impose a hard budget constraint (i.e., in equilibrium the lender strictly prefers to continue, $e^{*} R>L$ ). The entrepreneur's payoff function is

$$
U(e)= \begin{cases}e(\Pi-R)-\psi(e) & \text { for } e \geq e^{\prime}=L / R>e^{*} \\ -\psi(e) & \text { for } e<e^{\prime}\end{cases}
$$


Thus, $e^{*}$ is incentive compatible if and only if

$$
\Pi-R-\psi^{\prime}\left(e^{*}\right)=0
$$

and $U\left(e^{*}\right)=e^{*}(\Pi-R)-\psi\left(e^{*}\right) \geq \max _{e}-\psi(e)=0$, which holds with strict inequality by (IR) and $V-s \geq w>0$. Thus, (5) is necessary and sufficient for incentive-compatibility. The lender's problem reduces to

$$
\begin{array}{ll}
\max _{e^{*}} & e^{*}\left(\Pi-\psi^{\prime}\left(e^{*}\right)\right)-(1-w) \\
\text { s.t. } & \\
& e^{*} \psi^{\prime}\left(e^{*}\right)-\psi\left(e^{*}\right) \geq V-s=e^{F B} \Pi-\psi\left(e^{F B}\right)-(1-w+s)
\end{array}
$$

Recall that $e^{M}$ denotes the solution of the unconstrained problem, i.e., the unique solution of (2), and $e^{S B}(s)$ denotes the unique solution of (IR"). At $s=s^{\prime}$, (IR") must be binding. If it were slack, we would have $e^{*}=e^{M}$. Yet,

$$
e^{M} \psi^{\prime}\left(e^{M}\right)-\psi\left(e^{M}\right)=e^{M}(\Pi-R)-\psi\left(e^{M}\right)<e^{M} \Pi-\psi\left(e^{M}\right)-L<V-s^{\prime}=e^{F B} \Pi-\psi\left(e^{F B}\right)-L
$$

by $e^{M} R>L$ and $e^{M}<e^{F B}$, and hence (IR") would be violated. There thus is a threshold $\check{s}>s^{\prime}$ such that (IR") is slack if and only if $s \geq \check{s}$. We assume $\check{s}<V-w$. Let then $P(s)$ denote the lender's profit when (IR") is binding,

$$
P(s)=e^{S B}(s) \Pi-\psi\left(e^{S B}\right)-\left(e^{F B} \Pi-\psi\left(e^{F B}\right)\right)+s
$$

Notice that $P\left(s^{\prime}\right)<L-(1-w)$ by $e^{S B}(s)<e^{F B}$. Furthermore,

$$
P^{\prime}(s)=\frac{d e^{S B}(s)}{d s}\left(\Pi-\psi^{\prime}\left(e^{S B}(s)\right)\right)+1=-\frac{1}{e^{S B}(s) \psi^{\prime \prime}\left(e^{S B}(s)\right)}\left(\Pi-\psi^{\prime}\left(e^{S B}(s)\right)\right)+1>0
$$

by (2) and $e^{S B}(s)>e^{M}$ for $s<\check{s}$ (hence, $\left.\Pi-\psi^{\prime}\left(e^{S B}(s)\right)-e^{S B}(s) \psi^{\prime \prime}\left(e^{S B}(s)\right)<0\right)$. In other words, $P(s)$ is strictly increasing in $s$. Thus, since $P\left(s^{\prime}\right)<L-(1-w)$ and $P(\check{s})=e^{M}\left(\Pi-\psi^{\prime}\left(e^{M}\right)\right)-$ $(1-w)>L-(1-w)$ by $(3)$, there is a threshold $\hat{s} \in\left(s^{\prime}, \check{s}\right)$ where $P(\hat{s})=L-(1-w)$, i.e., the lender impose a hard budget constraint if and only if $s \leq \hat{s}$. 